УДК 330.101.542:005.44(438)

ББК 65.049

ДОМАШНЕЕ ХОЗЯЙСТВО В КОНСТЕКСТЕ ГЛОБАЛИЗАЦИИ: ПЕРСПЕКТИВЫ ИСПОЛЬЗОВАНИЯ ОПЫТА ПОЛЬШИ ДЛЯ БЕЛАРУСИ

\author{
П. А. ЯНОВИЧ \\ yanovich@bntu.by \\ аспирант \\ Белорусский государственный университет \\ Минск, Республика Беларусь
}

Глобализачию можно рассматривать как один из основных факторов формирования современных экономических прочессов. Либерализаџия и интеграция рынков, которая опирается на достижение научно-технической револючии, качественно формирует политическую и экономическую среду. Глобальная экономическая система становится все сложнее и сложнее. Последствием всего этого является изменение в поведении субъектов рынка - не только предприятий, но и домашних хозяйств. В случае Польши с надлежашим участием в международном сотрудничестве экономического, политического, научного, культурного и социального характера, это произошло только с конца 1980-х годов. Последние десятилетия для польских домашних хозяйств это период новой сочиально-экономической реальности.

Ключевые слова: глобализация, корпорации, государство, домашнее хозяйство, факторы производства, потребление, потребительский спрос.

\title{
HOUSEHOLD IN THE CONSTRUCTION OF GLOBALIZATION: PROSPECTS OF USE OF POLISH EXPERIENCE FOR BELARUS
}

\author{
P. A. YANOVICH \\ postgraduate student \\ Belarusian State University \\ Minsk, Republic of Belarus
}

Globalization is considered as one of the major factors shaping modern economic processes. Liberalization and integration of markets, which are based on the achievement of scientific and technological revolution, qualitatively forms the political and economic environment. The global economic system becomes more and more complex. The consequence of that is a change in behavior of market participants - not only enterprises, but also households. In case of Poland, with proper participation in international economic, political, scientific, cultural and social cooperation, it was not until the late 1980s. The last decades for Polish households can be viewed as a period of a new socio-economic reality.

Keywords: globalization, corporations, state, household, factors of production, consumption, consumer demand.

\section{ВВЕДЕНИЕ}

Термин «глобализация» часто появляется в дискуссиях о направлениях эволюции глобальной экономики за последние два десятилетия. Хотя этот процесс оказывает 
огромное влияние на изменения в глобальном измерении, недостатком является его единообразное, общепризнанное определение. Это в основном связано с динамикой и сложностью этого явления.

\section{РЕЗУЛЬТАТЫ И ИХ ОБСУЖДЕНИЕ}

Глобализация связана с функционированием человеческой цивилизации в нескольких областях: экономической, информационной, культурной, политической и экологической. Таким образом, глобализация определяется как сжатие времени и пространства, границ и ликвидации географических барьеров при перемещении товаров, услуг, капитала, инвестиций, технологий и информации, расширением деловых операций над границами, ускорение глобальных взаимодействий, усиление международных связей, углубляющейся взаимозависимости. «По мере усиления глобализации и, соответственно, ужесточения конкурентной борьбы на мировых рынках товаров и услуг роль экономической интеграции возрастает» [1, с. 125].

В литературе по этому вопросу подчеркиваются определенные концепции глобализации, особенно в вопросе об изменении условий функционирования мировой экономики и ее результатах - события и процессы в одной части мира важны для отдельных организаций и обществ в разных уголках земного шара.

Факторы, которые влияют на поведение домашних хозяйств в Польше, являются глобализация и европейская интеграция. Кроме того, этот процесс связан с быстрым техническим прогрессом, который в особенности связан с современным потреблением.

Основные тенденции глобализации касаются изменениям потребительского поведения фермерских и домашних хозяйств. Представляется целесообразным провести анализ изменения в поведении домашних хозяйств в условиях глобализации и ответить на вопрос, изменилось ли потребление в Польше в рамках процесса глобализации, и в какой степени отдельно следует рассматривать вопрос изменения потребления выбранных товаров длительного пользования, особенно в контексте технического прогресса. Развитие Интернета также должно быть связано с процессом глобализации, поэтому представляется важным признать использование информации, технологий и телекоммуникаций домашних хозяйств в Польше.

Особенности современного этапа глобализации ясно указывают на сложность и многомерность этого процесса. Это также является основной причиной отсутствия единого подхода к анализируемому явлению.

Следует подчеркнуть, что процессы глобализации не могут быть сведены к одному параметру, который всем управляет. Полное объяснение этого требует рассмотрения взаимодействие друг с другом политических, экономических, технологических, экологических сил, психологических и других аспектов. Поэтому нет никакой движущей единой силы глобализации, также трудно определить начало этого явления [2, p. 42]. Более того, эти факторы как детерминанты процесса глобализации являются одновременно и его последствия. Глобализация рассматривается как процесс с неопределенным результатом, а её траектория также зависит от противоположных явлений, которые появляются одновременно в международной и внутренней политике государств [2, p. 43].

Среди наиболее важных экономических субъектов в мире и основными участниками процесса глобализации являются государства и международные корпорации. По мнению Р. Пясецкого, большинство экономистов придерживаются мнения о том, что «транснациональные корпорации являются одной из основных сил глобализации» [3, p. 76].

Транснациональные корпорации являются основными агентами глобализации и имеют огромное значение в мировой торговле, глобальном производстве и глобальном 
технологическом потенциале и их роль всё увеличивается $[4$, р. 5]. Ранее, в основном, они использовали функции распределения ресурсов, принадлежащих государственным органам или рынкам. Они также играют важную роль в процессе глобализации страны для развития высоких технологий $[5$, p. 15]. Они не ведут напрямую экономическую деятельность, но через экономическую и внешнюю политику создают условия, способствующие тому же процессу глобализации, что и другие объекты в этом процессе.

Фермерские и домашние хозяйства также должны быть включены в группу заинтересованных сторон в процессе глобализации. Они участвуют в этом процессе со стороны спроса, а также предложения. Однако доля этой группы в этом процессе имеет различный характер. Это связано с несколькими причинами. Из-за рассеивания домашних хозяйств их роль в современных процессах глобализации ограничена, поскольку отдельные домохозяйства имеют незначительное влияние на формирование экономических процессов в современном мире. Ярким примером этого является растущая роль финансовых институтов, в конечном счете, они являются «собственниками» фермерских и домашних хозяйства через систему кредитования. В результате домохозяйства не имеют реальной ценности воздействие на деятельность основных участников процесса глобализации международные корпорации. Также влияние домашних хозяйств на правительства стран сильно ограничено моделью, функционирующей в большинстве стран.

Домашние хозяйства играют важную роль в глобальном обеспечении факторов производства. Что касается современных потоков капитала и технологий, то они практически неограниченны, а что касается рабочей силы, то этот процесс по-прежнему в значительной степени затруднен. Это связано как с особенностями этого фактора (включая языковые барьеры), там и с существующим ограничением на свободное передвижение людей. Объем миграции увеличиваются постепенно, хотя это не так спонтанно, как потоки капитала. Следует помнить, что производственный фактор в виде рабочей силы является важнейшим ресурсом каждого домохозяйства. Это имеет первостепенное значение для самого процесса глобализации. С другой стороны, технический прогресс позволяет выполнять определенные виды работ на расстоянии (дистанционная работа). В качестве второго аспекта следует учитывать долю домашних хозяйств в глобальном рынке товаров и услуг. Продолжающаяся глобализация экономической деятельности, технические и экономические изменения вызывают изменения в поведении и моделях потребление домашних хозяйств. Основные из них рассмотрим ниже для характеристики потребления и изменения поведения домохозяйства в последние годы [6, p. 137-163].

Экологизация потребления проявляется в экономическом и рациональном использовании потребительских товаров, а также во избежание большего количества потребления сырья, в результате чего могут возникать опасные отходы. Повышенная экологическая осведомленность членов домашних хозяйств, а также внутренние причины повышают интерес к потреблению натуральных продуктов от ограниченных производителей сельского хозяйства (биопродукты и здоровое питание) и изделий из натуральных материалов [7, р. 506-520].

Этическое потребление означает, что потребители сознательно отказываются от покупки товаров, неэтично произведенных (негуманное разведение животных, использование нелегальных работников и эмигрантов и низкооплачиваемая работа людей, в том числе детей). Это может также относиться к услугам, например, финансовым, то есть этические инвестиционные фонды, которые осуществляют деятельность в соответствии с принципами социального ответственного инвестирования [8].

Сервисизация потребления означает, что все большее значение вэкономике приобретает сектор услуг. Этот процесс во многом обусловлен техническим прогрессом (до- 
полнительные услуги для большой группы материальных благ), углубление технического разделения труда и замена определенных товаров услугами (например, ресторанные услуги). На феномен сервисизации потребления накладывается общий цивилизационный и культурный прогресс общества (повышение осведомленности и значимости для потребителей образования, здравоохранения, туризма, страхования и финансовых услуг), а также демографические процессы (старение обществ). «По нашему мнению, особенностью нового этапа развития экономических отношений является радикальное изменение механизмов организации обмена между производителями и потребителями. Рыночный сегмент, длительное время господствующий в экономически развитых странах, становится периферийным. Для пострыночной экономики характерно наличие высокоэффективного промышленного производства, значительное увеличение доли сектора услуг в ВВП, дальнейшее увеличение значения знаний для развития экономики, развитие интернет-технологий и новые (пострыночные) формы конкурентной борьбы. Собственно говоря, важнейшим отличием рыночной экономики от пострыночной экономики и выступают новые общественно-функциональные технологии, направленные на нелетальное разрушение социальных субъектов и ориентированные на противодействие этому разрушению» $[9$, с. 23$]$.

Централизация потребления в рамках семьи означает постепенную передачу потребления к домашнему хозяйству из различных типов государственных учреждений (например, кинотеатров, филармонии), благодаря большему использованию различного оборудования домашних хозяйств в товарах длительного пользования (телевизоры, hi-fi оборудование). Этот процесс резко усилился после разработки электронных средств межличностного общения (мобильная телефония, интернет). Это, в свою очередь, вызывает изменения в месте и способе удовлетворения потребностей (например, электронное обучение, телемедицина, электронный банкинг).

Гомогенизаџия общества и тенденция к подражанию расширяет глобальный потребительский рынок и рынок глобальных продуктов и брендов. Некоторые сегменты и товарные рынки становятся однородными в глобальном измерении и предлагают аналогичные продукты с точки зрения стандартов и удобства использования (электроника, компьютеры, автомобили, фаст-фуд). Это связано с тем, что все больше и больше товаров, произведенных в отдельных странах, являются предметом торгового обмена $[10$, p. 28]. Интенсивный и массовый туризм, а также быстрый поток информации ускоряет процессы гомогенизации, поскольку это облегчает коммуникации и межкультурные связи. Поэтому основные аспекты глобализации включают процессы унификации потребностей, отношения покупателей, а предпочтения в мире становятся похожими [11, p. 31]. Это происходит во всех моделях потребления, независимо от того, рассмотрено это в социально-экономическом или географическом разрезе. В связи с постепенным процессом унификации вкусов, потребностей, предпочтений, потребление превращается в так называемый «процесс макдональдизации» [12, р. 26-28].

Виртуализация потребностей происходит все больше и больше с помощью электронных средств массовой информации (интернет, ТВ). В то же время происходит создание и рост виртуального мира - разделение жизни людей на реальный и виртуальный мир.

Изменения в обычаях, которые относятся не только к сфере потребления, но также для управления свободным временем. Происходит индивидуализация потребительского поведения, что отражается на отходе от коллективного потребления (например, в рамках семьи). В то же время в связи со сжатием времени, потребители все чаще становятся заинтересованы в готовых потребительских продуктах. В социальной сфере глобализация привела к экономической эмансипации молодежи и пожилых людей и изменению 
модели семьи. В последние годы наблюдается затухание традиционных разделений ролей на мужское и женское. Кроме того, образ жизни разных возрастов и социальных групп стал схож.

Однако экопотребление и этическое потребление по-прежнему являются маргинальными явлениями. В глобальном масштабе они почти исключительно касаются домашних хозяйств в высокоразвитых странах [6, p. 138-139]. Другие обсуждаемые тенденции в моделях потребления домашних хозяйств фактически углубляются. Следует также подчеркнуть, что описанные выше изменения в моделях потребления домохозяйства влияют на других участников процесса глобализации. Результатом этого являются изменение поведения предприятий и финансовых учреждений, которые пытаются заполнить ниши развивающихся рынков (например, органическое земледелие, электронное банковское дело, прямое страхование).

Домохозяйства могут рассматриваться как важные субъекты процесса глобализации. Их участие в анализируемом процессе следует рассматривать в первую очередь в контексте изменений моделей потребительского спроса, которые возникают с основных характеристик процесса глобализации. Таким образом, он связан с обратным взаимодействием между домохозяйствами и другими заинтересованными сторонами глобализации. Это углубляет и ускоряет дальнейшие преобразования глобальной экономики. Следует учесть, что, хотя процесс глобализации в настоящее время учитывается почти в каждом хозяйстве, ее роль как единого субъекта, глобальной экономики очень мала. Это только изменения в модели поведения всей группа хозяйства (включая все домашние хозяйства), которые имеют важное значение для функционирования всех рынков.

Глобализация, как один из элементов субъектов рынка, обусловливает их поведение. Этот процесс затрагивает и домашние хозяйства. Участие белорусских домашних хозяйств в процессе глобализации трудно определить однозначно, поскольку до сих пор не принято общепринятого индекса, определяющего степень глобализации экономики. «В современном глобализирующемся мире ни одно государство не может обеспечить свое устойчивое социально-эколого-экономическое развитие без непрерывного роста социального потенциала общества в целом, групп и классов в него входящих, отдельных индивидов. Именно увеличение социального потенциала на всех уровнях - вот важнейшая предпосылка социально-экономической, экономической, политической и экологической безопасности Беларуси» [13, с. 5-6]. Следует отметить, что представленные аспекты воздействия процесса глобализации на домохозяйства не полностью раскрывают эти проблемы. Изменение спроса потребления, в том числе из-за ускорения темпа роста и поляризации доходов, которыми обладают хозяйствующие субъекты, неразрывно связаны с процессом глобализации.

\section{СПИСОК ИСПОЛЬЗОВАННЫХ ИСТОЧНИКОВ}

1. Солодовников, С. Ю. Евразийская экономическая интеграция / С. Ю. Солодовников, Ю. В. Мелешко // Весці Нацыянальнай акадэміі навук Беларусі. Серыя гуманітарных навук / Национальная академия наук Беларуси; редкол.: А. А. Каваленя (гл. ред.) [и др.]. - Минск: Беларуская навука, 2016. - № 3. - С. 121-125.

2. Pietraś, M. Globalizacja jako proces zmiany społeczności międzynarodowej [w:] / M. Pietraś // Oblicza procesów globalizacji, red. M. Pietraś. - Wydawnictwo Uniwersytetu Marii Curie-Skłodowskiej, Lublin 2002. - 300 s.

3. Piasecki, R. Rozwój gospodarczy a globalizacja / P. Piasecki // Ekonomia rozwoju W zderzeniu z rzeczywistością. Pietraś. - M PWE, Warszawa 2003. - 288 s. 
4. Liberska, B. Globalizacja - próba racjonalnego podejścia / B. Liberska // Nowe Życie Gospodarcze. - 2001. - nr 2.

5. Müller, A. Globalizacja - mit czy rzeczywistość? / A. Müller // "Bank i Kredyt". Dodatek Globalizacja od A do Z. - 2003. - nr 5. - 284s.

6. Bywalec, C. Konsumpcja w teorii i praktyce gospodarowania / C. Bywalec. Wydawnictwo Naukowe PWN, Warszawa 2007. - 224s.

7. Zob. też G. Antonides, W. F. van Raaij, Zachowanie konsumenta. Podręcznik akademicki, Wydawnictwo Naukowe PWN, Warszawa 2003. - 605 s.

8. Borkowski, T. Bezgrzeszne inwestycje // "Gazeta Bankowa". - 2008. - nr 21.

9. Солодовников, С. Ю. Феноменологическая природа взаимообусловленности экономической конкурентоспособности и социального капитала Беларуси и Украины // Экономическая наука сегодня: сборник научных статей / пред. редкол. С.Ю. Солодовников. - Минск: БНТУ, 2015. - Вып. 3. - С. 23-34.

10. Globalizacja. Mechanizmy i wyzwania, red. B. Liberska, PWE. - Warszawa 2002. $-342 \mathrm{~s}$.

11. Zorska, A. Ku globalizacji? Przemiany w korporacjach transnarodowych i w gospodarce światowej / A. Zorska // Wydawnictwo Naukowe PWN. - Warszawa 2000. - 260 s.

\section{REFERENCES}

1. Solodovnikov, S. Yu. Evrazijskaya ehkonomicheskaya integraciya / S. Yu. Solodovnikov, Yu. V. Meleshko // Vesci Nacyyanal'naj akadehmii navuk Belarusi. Seryya gumanitarnyh navuk / Nacional'naya akademiya nauk Belarusi; redkol.: A. A. Kavalenya (gl. red.) [i dr.]. - Minsk: Belaruskaya navuka, 2016. - № 3. - S. 121-125.

2. Pietraś, M. Globalizacja jako proces zmiany społeczności międzynarodowej [w:] / M. Pietraś // Oblicza procesów globalizacji, red. M. Pietraś. - Wydawnictwo Uniwersytetu Marii Curie-Skłodowskiej, Lublin 2002. - 300 s.

3. Piasecki, R. Rozwój gospodarczy a globalizacja / P. Piasecki // Ekonomia rozwoju w zderzeniu z rzeczywistością. Pietraś. - M PWE, Warszawa 2003. - 288 s.

4. Liberska, B. Globalizacja - próba racjonalnego podejścia / B. Liberska // Nowe Życie Gospodarcze. - 2001. - nr 2.

5. Müller, A. Globalizacja - mit czy rzeczywistość? / A. Müller // "Bank i Kredyt". Dodatek Globalizacja od A do Z. - 2003. - nr 5. - 284s.

6. Bywalec, C. Konsumpcja w teorii i praktyce gospodarowania / C. Bywalec. Wydawnictwo Naukowe PWN, Warszawa 2007. - 224s.

7. Zob. też G. Antonides, W. F. van Raaij, Zachowanie konsumenta. Podręcznik akademicki, Wydawnictwo Naukowe PWN, Warszawa 2003. - 605 s.

8. Borkowski, T. Bezgrzeszne inwestycje // "Gazeta Bankowa". - 2008. - nr 21.

9. Solodovnikov, S. Yu. Fenomenologicheskaya priroda vzaimoobuslovlennosti ehkonomicheskoj konkurentosposobnosti i social'nogo kapitala Belarusi i Ukrainy // EHkonomicheskaya nauka segodnya: sbornik nauchnyh statej / pred. redkol. S.Yu. Solo-dovnikov. Minsk: BNTU, 2015. - Vyp. 3. - S. 23-34.

10. Globalizacja. Mechanizmy i wyzwania, red. B. Liberska, PWE. - Warszawa 2002. $-342 \mathrm{~s}$.

11. Zorska, A. Ku globalizacji? Przemiany w korporacjach transnarodowych i w gospodarce światowej / A. Zorska // Wydawnictwo Naukowe PWN. - Warszawa 2000. - 260 s.

Статья поступила в редакциюю 22 марта 2018 года. 